\title{
Association of soluble endothelial protein C receptor plasma levels and $P R O C R$ rs867186 with cardiovascular risk factors and cardiovascular events in coronary artery disease patients: The Athero Gene Study
}

\author{
Choumous Kallel ${ }^{1}$, William Cohen ${ }^{1}$, Noémie Saut ${ }^{1}$, Stefan Blankenberg ${ }^{2}$, Renate Schnabel ${ }^{2}$, Hans J Rupprecht ${ }^{3}$, \\ Christoph Bickel ${ }^{4}$, Thomas Munzel ${ }^{3}$, David-Alexandre Tregouet $^{5}$ and Pierre-Emmanuel Morange ${ }^{1 *}$
}

\begin{abstract}
Background: Blood coagulation is an essential determinant of coronary artery disease (CAD). Soluble Endothelial Protein C Receptor (SEPCR) may be a biomarker of a hypercoagulable state. We prospectively investigated the relationship between plasma sEPCR levels and the risk of cardiovascular events (CVE).

Methods: We measured baseline sEPCR levels in 1673 individuals with CAD (521 with acute coronary syndrome [ACS] and 1152 with stable angina pectoris [SAP]) from the AtheroGene cohort. During a median follow up of 3.7 years, 136 individuals had a CVE. In addition, 891 of these CAD patients were genotyped for the PROCR rs867186 (Ser219Gly) variant.

Results: At baseline, sEPCR levels were similar in individuals with ACS and SAP (median: $111 \mathrm{vs.} 115 \mathrm{ng} / \mathrm{mL}$ respectively; $\mathrm{p}=0.20$ ). Increased $s E P C R$ levels were found to be associated with several cardiovascular risk factors including gender ( $p=0.006)$, soluble Tissue Factor levels $(p=0.0001)$, diabetes $(p=0.0005)$, and factors reflecting impaired renal function such as creatinine and cystatin $C(p<0.0001)$. sEPCR levels were not significantly associated with the risk of CVE (median: 110 and $114 \mathrm{ng} / \mathrm{mL}$ in individuals with and without future CVE respectively; $\mathrm{p}=0.68$ ). The rs867186 variant was found to explain $59 \%$ of $s E P C R$ levels variability $\left(p<10^{-200}\right)$ but did not associate with CVE risk.
\end{abstract}

Conclusion: Our findings show that in patients with CAD, circulating SEPCR levels are related to classical cardiovascular risk factors and renal impairment but are not related to long-term incidence of CVE.

Keywords: $\backslash$, Haemostasis, Protein C, Endothelial protein C receptor, Coronary artery disease

\section{Background}

Coronary artery disease (CAD) is the leading cause of death in the developed world [1]. It is an inflammatory process that involves cellular and molecular responses to endothelial dysfunction [2]. One such response is blood coagulation, and recent studies demonstrate that blood coagulation is an essential determinant of the risk of CAD complications $[2,3]$.

\footnotetext{
* Correspondence: pmorange@ap-hm.fr

'INSERM UMR_1062, Aix-Marseille Université, Marseille F-13385, France Full list of author information is available at the end of the article
}

The protein $\mathrm{C}(\mathrm{PC})$ anticoagulant pathway plays a pivotal role in controlling thrombosis and in limiting the inflammatory response. It may also reduce endothelial cell apoptosis in response to inflammatory cytokines and ischemia [3,4]. The endothelial PC receptor (EPCR) is important to these processes. Mainly expressed on the endothelial cells of large vessels [5-7], by binding to PC, EPCR accelerates the rate of PC activation approximately twenty fold in vivo [8]. Once PC is activated (Activated PC, APC), EPCR also mediates its antiapoptotic effect on endothelial cells [9]. 
In addition to endothelial cell-bound EPCR, a soluble form of EPCR (sEPCR) circulates in human plasma resulting from EPCR membrane shedding mediated by a metalloprotease $[7,10]$, probably TACE/ADAM17 [11]. This process occurs constitutively and is amplified by thrombin and some inflammatory cytokines (e.g., TNF $\alpha$, IL- $1 \beta$ ) [4,11]. sEPCR binds PC and APC with the same affinity as the original membrane form of EPCR and may inhibit both PC activation and APC anticoagulant activity [12]. In addition, sEPCR modulates inflammation by binding to activated neutrophils $[13,14]$ and also reportedly binds to factor VIIa, reducing the ability of FVIIa to activate FX [15]. Moreover, high levels of plasma sEPCR were observed in patients with clinical conditions in which thrombin is generated, such as CAD [13,16], and decreased sEPCR levels were observed in another study of patients on anticoagulant therapy [14].

These data all suggest that sEPCR may act as a procoagulant by reducing antithrombotic and anti inflammatory effects. However, data regarding the association between sEPCR plasma levels and the risk of thrombosis are sparse and contradictory. Uitte de Willige et al.[17], reported that a high level of sEPCR increased the risk of venous thrombosis, whereas another retrospective case/control study showed that patients with increased sEPCR levels had a reduced risk of myocardial infarction (MI) [18].

Several studies demonstrated that sEPCR levels were strongly genetically controlled [17-22]. The rs867186 diallelic single nucleotide polymorphism in the PROCR gene (g.6936A_G, c.4600A_G), resulting in a serine-to glycine substitution at codon 219 in the membranespanning domain of EPCR, explains between $56 \%$ and $87 \%$ of the variations in sEPCR levels $[17,20,23]$. The G allele tags the A3 haplotype (4 common PROCR haplotypes have been identified in whites) and is associated with increased shedding of EPCR from the endothelial membrane, both by rendering the receptor more sensitive to cleavage [24] and by leading to a truncated mRNA through alternative splicing [25]. Besides this important genetic effect, little is known about the association between sEPCR plasma levels and other environmental cardiovascular risk factors.

Since markers of procoagulable state are of major relevance to CAD, sEPCR could be a risk factor or a predictor of cardiovascular events (CVE) in individuals with CAD. We tested this hypothesis in the AtheroGene prospective cohort. We also studied the relation between sEPCR levels and conventional cardiovascular risk factors.

\section{Methods}

\section{Study population}

The Athero Gene study is a prospective cohort of CAD patients enrolled during several successive phases of recruitment between November 1996 and February 2004 [26]. Briefly, patients who underwent coronary angiography at the Medical Department of the Johannes Gutenberg-University Mainz or the Bundeswehrzentralkrankenhaus Koblenz and who had at least one stenosis $>30 \%$ diagnosed in a major coronary artery were enrolled in the cohort. Unstable angina was classified by Braunwald classification (class B or C). Follow-up information was obtained on non-fatal myocardial infarction (MI) and on death from cardiovascular (CV) causes (fatal MI, heart failure as a consequence of MI, ventricular arrhythmia, fatal stroke and other cause of vascular deaths). Information on the cause of death was obtained from the hospital or from the patient's general practitioner.

Among patients recruited in the early phase of the study, insufficient plasma remained for sEPCR testing. Therefore, this study included only patients recruited after June 1999 ( $\mathrm{n}=1673$ - second round of the AtheroGene Study). Among these, 525 (31\%) presented an acute coronary syndrome (ACS) at entry (314 unstable angina and 211 acute MI). The remaining individuals presented a stable angina pectoris (SAP) at entry. All individuals were followed up for a median time of 3.7 years (maximum 6.2) and 136 experienced a CVE (71 non-fatal MI and $65 \mathrm{CV}$ deaths).

Study participants had German nationality, were inhabitants of the Rhein-Main area, and were of European descent. The study was approved by the ethics committee of the University of Mainz. Participation was voluntary, and each participant gave written informed consent.

\section{Laboratory methods}

Blood was drawn from all study subjects under standardized conditions before coronary angiography was performed. Samples were stored at $-80^{\circ} \mathrm{C}$ until analysis. Plasma sEPCR levels were measured by enzyme linked ImmunoSorbent Assay (ELISA) according to the manufacturer's instructions. The asserachrom sEPCR ELISA kits were from Diagnostica Stago (Asnière, France) and the inter-assay variability was $7.5 \%$. Other biological parameters were measured as previously described [27].

\section{Genotype analysis}

DNA was available in a subsample of 891 CAD patients among which 77 experienced a CVE during the followup. In these patients, five PROCR single nucleotide polymorphisms (SNPs), including the PROCR rs867186 (Ser219Gly), were typed using the Affymetrix GenomeWide Human SNP 6.0 array as part of a previously described genome-wide association study [28]. 


\section{Statistical analysis}

Associations between baseline cardiovascular risk factors and CVE were tested by ANOVA and $\mathrm{Chi}^{2}$ analyses. Associations between sEPCR levels, haemostatic parameters and other cardiovascular risk factors were investigated through Pearson correlation coefficients adjusted for age and sex. sEPCR was log transformed to remove positive skewness. The relationship between sEPCR (considered as continuous variables or interquartiles) and CVE was tested by Cox regression analysis. Two models were successively fitted: model 1 was first adjusted for age and sex; model 2 was additionally adjusted for clinical status (ACS vs. stable angina), smoking status, body mass index, diabetes, hypertension, HDL-cholesterol, triglyceride, CRP, number of stenosed vessels, and medication use (heparin, beta-blockers, ACE-inhibitors, calcium antagonists and statins).

Association of PROCR SNPs with CVE was tested by the Cochran-Armitage trend test [29] and by a Cox regression analysis, while their association with log sEPCR levels was tested by a linear model. Linkage disequilibrium and haplotype analyses of PROCR SNPs were conducted using the THESIAS software [30].

All analyses were performed with SAS software, version 9.1 (SAS Institute Inc., Cary,NC, USA). P-values $<0.05$ were considered statistically significant.

\section{Results}

Baseline characteristics of individuals according to cardiovascular outcome

Table 1 shows the baseline characteristics of the CAD patients according to outcome. In the group with occurrence of CVE during follow-up, there was a higher proportion of females, patients presented more often with an ACS and with a history of previous MI, and a higher prevalence of diabetes was observed. The number of stenosed coronary arteries was also higher in this group. There was a marked increase in CRP, TAFIa/TAFIai and TFPI levels, and a slight elevation in D-dimer levels. Factors reflecting deteriorationof renal function such as creatinin and cystatin $\mathrm{C}$ were also markedly increased.

\section{Association between sEPCR levels and cardiovascular risk factors}

sEPCR levels were similar in patients with ACS at baseline compared to those with SAP at baseline $(\mathrm{p}=0.20$; Table 2). The highest correlations between sEPCR and other biological measurements were observed for creati$\operatorname{nin}(\mathrm{r}=0.14)$ and cystatin $\mathrm{C}(\mathrm{r}=0.17)$ (Table 2). Other significant correlations were found with soluble tissue factor (sTF) $(r=0.11)$ and total amount of TAFI (t-TAFI) $(r=0.08)$. Plasma sEPCR levels were higher in males and in diabetic patients, but were decreased in smokers.

\section{Association between sEPCR levels and cardiovascular outcome}

sEPCR levels were not significantly different between individuals with or without future CVE, regardless of whether sEPCR was studied as continuous variable or in quartiles (Table 3). Likewise, there was no significant association when individuals with ACS at baseline were studied separately from those with SAP at baseline (data not shown).

\section{PROCR SNPs analysis}

In the subsample of CAD patients with DNA available, five PROCR SNPs were genotyped: rs6088738, rs6088747, rs2069940, rs867186 and rs1415774. These SNPs were in strong linkage disequilibrium, with rs6088747 and rs867186 being in complete association (pairwise $\mathrm{r}^{2} \sim 1$ ) with $\mathrm{rs} 1415774$ and $\mathrm{rs} 2069940$, respectively (Table 4). None of these SNPs were associated with the risk of future CVE (Table 5). In particular, the allele frequency of the rs867186-G allele was 0.11 both in patients with and without future CVE (Table 5). As expected, the rs867186 variant was strongly associated with sEPCR levels and explained 59.1\% $\left(\mathrm{p}<10^{-200}\right)$ of their variability. The rs867186-G allele was associated with increased sEPCR levels in a fairly additive fashion, the observed log sEPCR levels being $4.66 \pm 0.29,5.48 \pm 0.26$

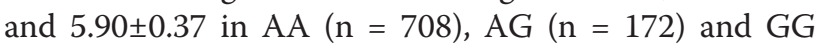
$(\mathrm{n}=11)$ carriers. This association was homogeneous in patients with or without future CVE, in men and in women, and was not modified after adjusting for the studied cardiovascular risk factors (data not shown). Further haplotype analysis revealed that the rs867186-G allele was carried out by a single haplotype, that was the only one associated with sEPCR levels (Table 6).

Of note, in this sample, the Hazard Ratio (HR) for future CVE associated with an increase of log-sEPCR (on continuous scale) was 0.84 [0.35 - 2.02] $(\mathrm{p}=0.69)$ in carriers of the rs867186 AA genotype while an opposite trend (HR of $4.88[0.87-27.4](\mathrm{p}=0.07)$ was observed in carriers of the rs867186-G allele. The test for homogeneity of these two HRs was borderline $(p=0.075)$.

\section{Discussion}

To the best of our knowledge, this is the first prospective study that investigates the association between sEPCR levels and CAD. Contrary to our initial hypothesis, there was no association between sEPCR levels and future CVE. Moreover both individuals with ACS and SAP at baseline had similar sEPCR levels.

Only one previously published case-control study examined the relationship between sEPCR levels and CAD [18]. In this work, stratification of sEPCR in quartiles according to the levels in controls showed that, compared to the first quartile, the OR for subjects with 
Table 1 Baseline characteristics of coronary artery disease (CAD) patients according to the outcome during follow-up

\begin{tabular}{|c|c|c|c|}
\hline Characteristics & No cardiovascular event $n=1537$ & Cardiovascular event $n=136$ & Association Test \\
\hline Age, years & $61.2 \pm 9.5$ & $62.8 \pm 10.5$ & $p=0.059$ \\
\hline Females & $323(21 \%)$ & $39(29 \%)$ & $p=0.050$ \\
\hline Acute coronary syndrome & $467(30 \%)$ & $58(43 \%)$ & $p=3.7810^{-3}$ \\
\hline Previous myocardial infarction & $586(38 \%)$ & $65(48 \%)$ & $p=0.028$ \\
\hline \multicolumn{4}{|c|}{ Number of stenosed coronary arteries } \\
\hline one vessel & $438(29 \%)$ & $21(15 \%)$ & \\
\hline two vessels & 479 (31\%) & $43(32 \%)$ & $p=1.3110^{-3}$ \\
\hline three vessels & $620(40 \%)$ & $72(53 \%)$ & \\
\hline Body mass index $\left(\mathrm{kg} / \mathrm{m}^{2}\right)$ & $27.7 \pm 3.9$ & $27.8 \pm 3.8$ & $p=0.927$ \\
\hline Current smoker & $304(20 \%)$ & $33(24 \%)$ & $p=0.219$ \\
\hline Diabetes mellitus & $240(16 \%)$ & $43(32 \%)$ & $p=1.1710^{-5}$ \\
\hline Hypertension & $1151(75 \%)$ & $105(77 \%)$ & $p=0.606$ \\
\hline \multicolumn{4}{|l|}{ Medications at enrollment } \\
\hline Heparin & $521(34 \%)$ & $55(40 \%)$ & $p=0.132$ \\
\hline Antiplatelet therapy & $1327(86 \%)$ & $108(79 \%)$ & $p=0.039$ \\
\hline Statins & $800(52 \%)$ & $68(50 \%)$ & $p=0.277$ \\
\hline Beta-blocker & $1026(67 \%)$ & $80(59 \%)$ & $p=0.072$ \\
\hline ACE-inhibitor & $770(50 \%)$ & $84(62 \%)$ & $p=9.4110^{-3}$ \\
\hline Calcium antagonists & $197(13 \%)$ & $25(18 \%)$ & $p=0.085$ \\
\hline Total cholesterol $\left(\mathrm{mgdL}^{-1}\right)$ & $197 \pm 45$ & $205 \pm 51$ & $p=0.038$ \\
\hline HDL-cholesterol $\left(\mathrm{mgdL}^{-1}\right)$ & $49.4 \pm 13.5$ & $48.1 \pm 13.6$ & $p=0.290$ \\
\hline Triglyceride $\left(\mathrm{mgdL}^{-1}\right)$ & $129(95-182)$ & $130(100-183)$ & $p=0.143$ \\
\hline $\mathrm{CRP}\left(\mathrm{mgL}^{-1}\right)$ & $2.39(1.02-6.14)$ & $4.59(1.89-11.7)$ & $p=8.4110^{-6}$ \\
\hline Fibrin monomers $(\mu \mathrm{mL})$ & $3.90(2.64-5.33)$ & $3.32(2.64-5.34)$ & $p=0.514$ \\
\hline D-dimers $\left(\mu \mathrm{gmL}^{-1}\right)$ & $0.34(0.24-0.52)$ & $0.39(0.25-0.78)$ & $p=0.024$ \\
\hline t-TAFI $\left(\mu \mathrm{g} \mathrm{mL}^{-1}\right)$ & $12.0 \pm 2.7$ & $12.4 \pm 2.7$ & $p=0.196$ \\
\hline$\overline{\text { TAFla/TAFlai }\left(\mathrm{ngmL}^{-1}\right)}$ & $10.48(8.13-13.95)$ & $11.59(9.00-15.08)$ & $p=2.7510^{-3}$ \\
\hline Soluble Tissue factor $\left(\mathrm{pgmL}^{-1}\right)$ & $158(124-204)$ & $159(124-208)$ & $p=0.641$ \\
\hline f-TFPI $\left(n g m L^{-1}\right)$ & $10.80(7.61-18.89)$ & $13.46(9.34-25.89)$ & $p=7.5410^{-3}$ \\
\hline Creatinine $\left(\mathrm{mgdL}^{-1}\right)$ & $0.96 \pm 1.03$ & $1.03 \pm 0.29$ & $p=5.5910^{-4}$ \\
\hline Cystatin C (mgL $\left.{ }^{-1}\right)$ & $0.81(0.71-0.94)$ & $0.86(0.72-1.08)$ & $p=1.2810^{-4}$ \\
\hline $\mathrm{sEPCR}\left(\mathrm{ngmL}^{-1}\right)$ & $114(93-161)$ & $110(91-177)$ & $p=0.654$ \\
\hline
\end{tabular}

t-TAFI measures total Thrombin Activating Fibrinolysis Inhibitor in plasma ; TAFla/TAFlai measures activated TAFI levels in plasma; f-TFPI = free form of tissue factor pathway inhibitor 1 .

Categorical variables are presented as $n(\%)$, and continuous variables as mean $\pm S D$ or median $\left(25^{\text {th }}-75^{\text {th }}\right.$ percentile) for skewed variables (for these variables, tests were performed on log-transformed distribution).

values in the $4^{\text {th }}$ quartile was 0.57 (95CI: 0.34-0.95). This result differs from ours, as we did not find a protective effect of high sEPCR levels in our cohort. Among the possible explanations for this discrepancy are differences in study design (retrospective versus prospective) and in the age of study participants at baseline (median age of 42 years in the case-control study versus 62 years in our prospective study). It could also be argued that the low number of events observed during the follow-up with median time of 3.7 years may have limited our power to detect any association of sEPCR with future CVE, especially if sECPR effects, if any, exert at a later time period.
Nevertheless, our study was large enough to detect the association of several biomarkers, including parameters characterizing the renal function, with the risk of future CVE.

The physiological role of sEPCR is still unclear. Elevated plasma sEPCR levels may increase thrombotic risk by inhibiting PC and APC and by competing with membrane associated EPCR for PC binding [12]. High plasma sEPCR levels might also result in low residual EPCR levels on the membrane, resulting in reduced PC activation. Alternatively, higher levels of endothelial or soluble EPCR may shift the haemostatic balance toward 
Table 2 Association between SEPCR, haemostatic parameters and other cardiovascular risk factors, adjusted for age and sex

\begin{tabular}{|c|c|c|}
\hline & sEPCR & \\
\hline & $\begin{array}{c}\text { Pearson's partial } \\
\text { correlation coefficients }\end{array}$ & $p$-value ${ }^{* 1}$ \\
\hline Age & 0.03 & $p=0.27$ \\
\hline Body mass index & 0.05 & $p=0.06$ \\
\hline Total cholesterol & -0.02 & $p=0.40$ \\
\hline HDL cholesterol & -0.02 & $p=0.31$ \\
\hline Triglyceride & 0.05 & $p=0.04$ \\
\hline CRP & -0.06 & $p=0.01$ \\
\hline Fibrin monomer & 0.02 & $p=0.48$ \\
\hline D-dimers & 0.00 & $p=0.89$ \\
\hline t-TAFI & 0.08 & $p=0.0007$ \\
\hline TAFla/TAFlai & 0.03 & $p=0.19$ \\
\hline Soluble Tissue factor & 0.11 & $p<0.0001$ \\
\hline f-TFPI & -0.02 & $p=0.38$ \\
\hline Creatinine & 0.14 & $p<0.0001$ \\
\hline \multirow[t]{2}{*}{ Cystatine C } & 0.17 & $p<0.0001$ \\
\hline & $\begin{array}{c}\text { Median } \\
\text { (interquartile range) }\end{array}$ & $p$-value ${ }^{* 2}$ \\
\hline \multicolumn{3}{|l|}{ Sex } \\
\hline Male & $116(94-166)$ & \\
\hline Female & $107(89-155)$ & $p=0.006$ \\
\hline \multicolumn{3}{|c|}{ Acute coronary syndrome } \\
\hline No & $115(94-166)$ & \\
\hline Yes & $111(90-156)$ & $p=0.20$ \\
\hline \multicolumn{3}{|l|}{ Current smoking } \\
\hline No & $115(94-170)$ & \\
\hline Yes & $108(88-148)$ & $p=0.005$ \\
\hline \multicolumn{3}{|l|}{ Diabetes } \\
\hline No & $111(91-158)$ & \\
\hline Yes & $123(101-182)$ & $p=0.0005$ \\
\hline \multicolumn{3}{|l|}{ Hypertension } \\
\hline No & $111(91-147)$ & \\
\hline Yes & $115(94-168)$ & $p=0.12$ \\
\hline
\end{tabular}

* Tests performed on correlations $\left({ }^{1}\right)$ or means $\left({ }^{2}\right)$ adjusted on age and sex; skewed variables were log-transformed.

anticoagulant activity by inhibiting the activation of FX by the FVIIa-tissue factor (TF) complex. Low sEPCR levels, on the other hand, also might reflect increased thrombotic risk. This could be caused by low EPCR expression on the endothelium or by membrane-bound EPCR that is resistant to ADAM17 shedding [24], resulting in decreased APC formation. Further studies are needed to investigate the relationship between EPCR membrane expression and its circulating form. Indeed, a recent study reported that $\mathrm{TNF} \alpha$ causes a rapid downregulation of membrane associated EPCR expression without markedly affecting the spontaneous release of sEPCR by arterial endothelial cells [31].

With respect to parameters affecting sEPCR levels, we confirmed in a subsample of 891 patients who had both sEPCR measured and DNA available the major impact of the Ser219Gly EPCR polymorphism on sEPCR levels [17-22]. However, we did not observe any evidence in favour of an association of Ser219Gly with future CVE. This is unlikely due to a loss power since the same allele frequencies were observed in both groups of patients with or without future CVE. Conversely, this is in line with a recent review demonstrating that this polymorphism is unlikely a risk variant for arterial thrombosis but more likely a risk variant for venous thrombosis [32]. Nevertheless, it would be highly interesting to investigate whether the trend of association observed between SEPCR and CVE risk in rs867186-G carriers only could replicate in a much larger cohort with a longer follow-up.

In addition, we have explored the association of plasma sEPCR levels with haemostatic variables. sEPCR levels correlated with sTF and t-TAFI levels. Previous studies demonstrated that sTF levels, but not t-TAFI, were predictive of cardiovascular death in individuals with $\mathrm{CAD}$ [27,33]. In atherosclerosis, circulating sTF can arise not only by membrane shedding but also by alternative splicing [34]. Several recent observations indicate that FVIIa interacts with EPCR in vivo [35]. Moreover, analysis of FVII, FVIIa, and sEPCR levels in a large group of healthy individuals revealed that those with higher sEPCR levels also had higher levels of circulating FVII and FVIIa [19]. The association observed between SEPCR and STF in the present study underlines the interplay between EPCR and the extrinsic coagulation pathway.

Several papers $[14,36]$ have previously suggested that sEPCR levels could be a reliable marker of thrombin generation. Our study did not favour this hypothesis as no relation was observed between sEPCR levels and markers of thrombin generation such as D-dimer, fibrin monomers, and TAFIa/TAFIai levels.

We also evaluated the relationship between sEPCR levels and traditional cardiovascular risk factors. We confirmed recent data [31] demonstrating that gender strongly correlates with sEPCR levels, with higher circulating SEPCR levels observed in males. We found a strong association between diabetes and SEPCR levels. These results are in line with those from Ireland et al. [23] who observed a contribution of duration of diabetes on sEPCR levels in the Ealing Diabetes Study of Coagulation (EDSC). Interestingly, we also found a strong correlation between SEPCR and parameters reflecting kidney functions such as creatinine and cystatin C. High sEPCR levels were reported in hemodialysis patients and significantly decreased after kidney transplantation [37]. This finding extends those already reported on the 
Table 3 Hazard ratios (95\% confidence interval) for cardiovascular death or myocardial infarction according to quartiles of baseline sEPCR levels

\begin{tabular}{lccccc}
\hline & Q1 & Q2 & Q3 & Q4 & p (continuous scale) \\
\hline Quartiles ranges & $48-93$ & $94-113$ & $114-162$ & $163-600$ & \\
\hline Patients with events/ all patients & $36 / 418$ & $35 / 418$ & $29 / 419$ & $36 / 418$ & \\
\hline Model 1 & reference & $1.00(0.63-1.60)$ & $0.85(0.52-1.39)$ & $1.03(0.65-1.64)$ & $\mathrm{p}=0.57$ \\
\hline \multicolumn{7}{l}{ Model 2 } & reference & $1.11(0.67-1.83)$ & $0.96(0.57-1.62)$ & $1.13(0.69-1.87)$ & $\mathrm{p}=0.38$ \\
\hline & & $\mathrm{p}=0.69$ & $\mathrm{p}=0.87$ & $\mathrm{p}=0.63$ & \\
\hline
\end{tabular}

Model 1: adjusted on age and sex; model 2: adjusted on age, sex, acute coronary syndrome, smoking status, body mass index, diabetes, hypertension, HDL-cholesterol, triglyceride, CRP, number of stenosed vessels, and medication use (heparin, beta-blockers, ACE-inhibitors, calcium antagonists and statins).

P-value was calculated on continuous log-transformed sEPCR.

Table 4 Pairwise linkage disequilibrium observed at the PROCR locus in the AtheroGene study $(\mathbf{n}=\mathbf{8 9 1})$

\begin{tabular}{|c|c|c|c|c|c|}
\hline & rs6088738 & rs6088747 & rs2069940 & rs867186 & rs1415774 \\
\hline rs6088738 & - & -0.97 & -0.93 & -0.93 & -1 \\
\hline rs6088747 & 0.21 & - & -0.98 & -0.98 & 0.99 \\
\hline rs2069940 & 0.03 & 0.09 & - & 1 & -1 \\
\hline rs867186 & 0.03 & 0.09 & 1 & - & -1 \\
\hline rs1415774 & 0.21 & 0.97 & 0.09 & 0.09 & 1 \\
\hline
\end{tabular}

Pairwise linkage disequilibium was expressed in terms of D' (upper-right triangle) and $r^{2}$ (bottom-left triangle) values.

Table 5 Genotype distribution of the PROCR polymorphisms in CAD patients according to the outcome during follow-up

\begin{tabular}{|c|c|c|}
\hline & $\begin{array}{l}\text { No cardiovascular } \\
\text { event } \mathrm{N}=805\end{array}$ & $\begin{array}{l}\text { Cardiovascular } \\
\text { events } \mathrm{N}=77\end{array}$ \\
\hline & \multicolumn{2}{|c|}{ rs6088738 } \\
\hline GG & 469 (59\%) & 46 (60\%) \\
\hline GA & $291(36 \%)$ & $28(36 \%)$ \\
\hline $\mathrm{AA}$ & 40 (5\%) & $3(4 \%)$ \\
\hline$\overline{M A F^{(1)}}$ & 0.232 & 0.221 \\
\hline \multirow[t]{2}{*}{$P^{(2)}$} & \multicolumn{2}{|c|}{$p=0.752$} \\
\hline & \multicolumn{2}{|c|}{ rs6088747 } \\
\hline$\pi$ & 280 (35\%) & 18 (24\%) \\
\hline TG & $380(47 \%)$ & $43(56 \%)$ \\
\hline GG & 145 (18\%) & $16(20 \%$ \\
\hline MAF & 0.416 & 0.487 \\
\hline \multirow[t]{2}{*}{ P } & \multicolumn{2}{|c|}{$p=0.092$} \\
\hline & \multicolumn{2}{|c|}{ rs867186 } \\
\hline $\mathrm{AA}$ & 639 (79\%) & $62(80 \%)$ \\
\hline$A G$ & 157 (20\%) & $13(17 \%)$ \\
\hline GG & $9(1 \%)$ & $2(3 \%)$ \\
\hline MAF & 0.109 & 0.110 \\
\hline$P$ & \multicolumn{2}{|c|}{$p=0.948$} \\
\hline
\end{tabular}

(1) MAF: Minor Allele Frequency.

(2) P-value of the Cochran-Armitage trend.

As rs2069940 and rs1415774 were in complete association with rs867186 and rs6088747, respectively, their genotype distributions were not displayed. association between coagulation parameters and kidney function [38].

\section{Conclusion}

In conclusion, we reported the first prospective study investigating the association of SEPCR with CAD. We observed no association between sEPCR levels and acute coronary syndrome or with future cardiovascular events. However, sEPCR levels were associated with conventional cardiovascular risk factors such as diabetes and parameters reflecting kidney function. More research is warranted to elucidate the pathogenic effect of sEPCR in CAD.

\section{Competing interests}

The authors declare that they have no competing interests.

\section{Authors' contributions}

$\mathrm{SB}, \mathrm{HJR}, \mathrm{CB}, \mathrm{TM}, \mathrm{DAT}$ and PEM contributed to the design of this study. NS, $\mathrm{SB}, \mathrm{RS}, \mathrm{HJR}, \mathrm{CB}$ and TM contributed to data acquisition. CK and WC participated to the statistical analysis of the data under the supervision of DAT. RS, DAT and PEM wrote the manuscript. All authors read and approved the final manuscript.

\section{Acknowledgements}

This work was supported by a grant of the Programme National de Recherche sur les Maladies Cardiovasculaires 2006 (A06034AS), by the "Stiftung Rheinland-Pfalz für Innovation", Ministry for Science and Education (AZ 15202-386261/545), Mainz, by the MAIFOR grant 2001 of the Johannes Gutenberg-University Mainz, Germany and by a grant from the Fondation de France (no. 2002004994).

\section{Author details}

${ }^{1}$ INSERM UMR_1062, Aix-Marseille Université, Marseille F-13385, France.

${ }^{2}$ Department of General and Interventional Cardiology, University Heart 
Table 6 Association of the main PROCR haplotypes with sEPCR (log) levels in the AtheroGene study $(\mathbf{n}=\mathbf{8 9 1})$

\begin{tabular}{|c|c|c|c|c|c|c|}
\hline \multicolumn{5}{|c|}{ Polymorphisms } & \multirow{2}{*}{$\begin{array}{l}\text { Haplotype } \\
\text { Frequencies }\end{array}$} & \multirow[t]{2}{*}{ Haplotypic Effects $^{*}$} \\
\hline rs6088738 & rs6088747 & rs2069940 & rs867186 & rs1415774 & & \\
\hline G & $\mathrm{T}$ & G & G & G & 0.108 & $+0.786[0.742-0.829] p=6.7410^{-27}$ \\
\hline G & $\mathrm{T}$ & C & A & G & 0.239 & $-0.027[-0.061-0.007] p=0.125$ \\
\hline G & G & C & A & A & 0.416 & reference \\
\hline A & $\mathrm{T}$ & C & A & G & 0.228 & $0.028[-0.009-0.066] p=0.143$ \\
\hline \multicolumn{5}{|c|}{ Global test for haplotypic association } & \multicolumn{2}{|c|}{$x^{2}$ with $3 \mathrm{df}=792.6 p=1.7110^{-171}$} \\
\hline
\end{tabular}

* Additive effects of each inferred haplotype compared to the most frequent one used as the reference haplotype. Effects were adjusted for age, sex, smoking and CV events.

Center Hamburg, Hamburg, Germany. ${ }^{3}$ Department of Medicine II, Johannes Gutenberg-University Mainz, Mainz, Germany. ${ }^{4}$ Federal Armed Forces Central Hospital Koblenz, Koblenz, Germany. ${ }^{5}$ INSERM, UMR_S 937; Institute of Cardiometabolism And Nutrition (ICAN), Université Pierre et Marie Curie Paris 6, Paris F-75013, France.

Received: 31 July 2012 Accepted: 12 October 2012

Published: 8 November 2012

\section{References}

1. World Health Organisation. Cardiovascular media-centre disease. www.who.int.

2. Lowe GD: Circulating inflammatory markers and risks of cardiovascular and non-cardiovascular disease. J Thromb Haemost 2005, 3:1618-1627.

3. Castellino FJ, Ploplis VA: The protein C pathway and pathologic processes. J Thromb Haemost 2009, 7:140-145.

4. Menschikowski M, Hagelgans A, Eisenhofer G, et al: Regulation of endothelial protein $C$ receptor shedding by cytokines is mediated through differential activation of MAP kinase signaling pathways. Exp Cell Res 2009, 315:2673-2682

5. Laszik Z, Mitro A, Taylor FB Jr, et al: Human protein C receptor is present primarily on endothelium of large blood vessels: implications for the control of the protein C pathway. Circulation 1997, 96:3633-3640.

6. Ye X, Fukudome K, Tsuneyoshi N, et al: The endothelial cell protein C receptor (EPCR) functions as a primary receptor for protein $C$ activation on endothelial cells in arteries, veins, and capillaries. Biochem Biophys Res Commun 1999, 259:671-677.

7. Esmon CT: Structure and functions of the endothelial cell protein C receptor. Crit Care Med 2004, 32:S298-S301.

8. Esmon CT: The endothelial cell protein C receptor. Thromb Haemost 2000, 83:639-643.

9. Cheng T, Liu D, Griffin JH, et al: Activated protein C blocks p53-mediated apoptosis in ischemic human brain endothelium and is neuroprotective. Nat Med 2003, 9:338-342.

10. Xu J, Qu D, Esmon NL, et al: Metalloproteolytic release of endothelial cell protein C receptor. J Biol Chem 2000, 275:6038-6044.

11. Qu D, Wang Y, Esmon NL, et al: Regulated endothelial protein $C$ receptor shedding is mediated by tumor necrosis factor-alpha converting enzyme/ADAM17. J Thromb Haemost 2007, 5:395-402.

12. Liaw PC, Neuenschwander PF, Smirnov MD, et al: Mechanisms by which soluble endothelial cell protein $C$ receptor modulates protein $C$ and activated protein C function. J Biol Chem 2000, 275:5447-5452.

13. Kurosawa S, Esmon CT, Stearns-Kurosawa DJ: The soluble endothelial protein $C$ receptor binds to activated neutrophils: involvement of proteinase-3 and CD11b/CD18. J Immunol 2000, 165:4697-4703.

14. Stearns-Kurosawa DJ, Swindle K, D'Angelo A, et al: Plasma levels of endothelial protein $C$ receptor respond to anticoagulant treatment. Blood 2002, 99:526-530.

15. Lopez-Sagaseta J, Montes R, Puy C, et al: Binding of factor Vlla to the endothelial cell protein $C$ receptor reduces its coagulant activity. J Thromb Haemost 2007, 5:1817-1824.

16. Kurosawa S, Stearns-Kurosawa DJ, Carson CW, et al: Plasma levels of endothelial cell protein $C$ receptor are elevated in patients with sepsis and systemic lupus erythematosus: lack of correlation with thrombomodulin suggests involvement of different pathological processes. Blood 1998, 91:725-727.
17. Uitte De Willige $S$, Van Marion V, Rosendaal FR, et al: Haplotypes of the EPCR gene, plasma sEPCR levels and the risk of deep venous thrombosis. J Thromb Haemost 2004, 2:1305-1310.

18. Medina P, Navarro S, Corral J, et al: Endothelial protein $C$ receptor polymorphisms and risk of myocardial infarction. Haematologica 2008, 93:1358-1363

19. Ireland HA, Cooper JA, Drenos F, et al: FVII, FVIla, and downstream markers of extrinsic pathway activation differ by EPCR Ser219Gly variant in healthy men. Arterioscler Thromb Vasc Biol 2009, 29:1968-1974

20. Medina P, Navarro S, Estelles A, et al: Contribution of polymorphisms in the endothelial protein $C$ receptor gene to soluble endothelial protein $C$ receptor and circulating activated protein $C$ levels, and thrombotic risk. Thromb Haemost 2004, 91:905-911.

21. Saposnik B, Reny $J$, Gaussem $P$, et al: $A$ haplotype of the EPCR gene is associated with increased plasma levels of SEPCR and is a candidate risk factor for thrombosis. Blood 2004, 103:1311-1318.

22. Yamagishi $K$, Cushman M, Heckbert SR, et al: Lack of association of soluble endothelial protein $C$ receptor and PROCR $6936 \mathrm{~A} / \mathrm{G}$ polymorphism with the risk of venous thromboembolism in a prospective study. $\mathrm{Br} J$ Haematol 2009, 145:221-226.

23. Ireland H, Konstantoulas CJ, Cooper JA, et al: EPCR Ser219Gly: elevated SEPCR, prothrombin $\mathrm{F} 1+2$, risk for coronary heart disease, and increased sEPCR shedding in vitro. Atherosclerosis 2005, 183:283-292.

24. Qu D, Wang Y, Song Y, Esmon NL, Esmon CT: The Ser219->Gly dimorphism of the endothelial protein $C$ receptor contributes to the higher soluble protein levels observed in individuals with the $\mathrm{A} 3$ haplotype. J Thromb Haemost 2006, 4:229-235.

25. Saposnik B, Lesteven E, Lokajczyk A, Esmon CT, Aiach M, Gandrille S: Alternative mRNA is favored by the $A 3$ haplotype of the EPCR gene PROCR andgenerates a novel soluble form of EPCR in plasma. Blood 2008, 111:3442-5126.

26. Rupprecht HJ, Blankenberg S, Bickel C, et al: Impact of viral and bacterial infections burden on long-term prognosis in patients with coronary artery disease. Circulation 2001, 104:25-31.

27. Tregouet DA, Schnabel R, Alessi MC, et al: Activated thrombin activatable fibrinolysis inhibitor levels are associated with the risk of cardiovascular death in patients with coronary artery disease: the AtheroGene study. J Thromb Haemost 2009, 7:49-57.

28. Wild PS, Zeller T, Schillert A, et al: A genome-wide association study identifies LIPA as a susceptibility gene for coronary artery disease. Circ Cardiovasc Genet 2011, 4:403-412.

29. Sasieni PD: From genotypes to genes: doubling the sample size. Biometrics 1997, 53:1253-1261.

30. Trégouët DA, Garelle V: A new JAVA interface implementation of THESIAS: testing haplotype effects in association studies. Bioinformatics 2007, 23:1038-1039.

31. Guitton C, Gerard N, Quillard T, et al: Circulating endothelial cell protein C receptor: endothelial regulation and cumulative impact of gender and a3 haplotype. J Vasc Res 2011, 48:336-346.

32. Dennis J, Johnson CY, Adediran AS, de Andrade M, Heit JA, Morange PE, Trégouët DA, Gagnon F: The endothelial protein $C$ receptor (PROCR) Ser219Gly variant andrisk of common thrombotic disorders: a HuGE review and meta-analysis of evidence from observational studies. Blood 2012, 119:2392-2400. 
33. Morange PE, Blankenberg S, Alessi MC, et al: Prognostic value of plasma tissue factor and tissue factor pathway inhibitor for cardiovascular death in patients with coronary artery disease: the AtheroGene study. J Thromb Haemost 2007, 5:475-482.

34. Bogdanov VY, Balasubramanian V, Hathcock J, et al: Alternatively spliced human tissue factor: a circulating, soluble, thrombogenic protein. Nat Med 2003, 9:458-462.

35. Sen $\mathrm{P}$, Gopalakrishnan R, Kothari $\mathrm{H}$, et al: Factor VIla bound to endothelial cell protein $C$ receptor activates protease activated receptor- 1 and mediates cell signaling and barrier protection. Blood 2011, 117:3199-3208.

36. Gu JM, Katsuura Y, Ferrell GL, Grammas P, Esmon CT: Endotoxin and thrombin elevate rodent endothelial cell protein $\mathrm{C}$ receptor mRNA levels and increase receptor shedding in vivo. Blood 2000, 95:1687-1693.

37. Keven K, Elmaci S, Sengul S, et al: Soluble endothelial cell protein C receptor and thrombomodulin levels after renal transplantation. Int Urol Nephrol 2010, 42:1093-1098.

38. Bash LD, Erlinger TP, Coresh J, et al: Inflammation, hemostasis and the risk of kydney function decline in the atherosclerosis risk in communities (ARIC) Study. Am J Kidney Dis 2009, 53:596-605.

doi:10.1186/1471-2350-13-103

Cite this article as: Kallel et al: Association of soluble endothelial protein C receptor plasma levels and PROCR rs 867186 with cardiovascular risk factors and cardiovascular events in coronary artery disease patients: The Athero Gene Study. BMC Medical Genetics 2012 13:103.

\section{Submit your next manuscript to BioMed Central and take full advantage of:}

- Convenient online submission

- Thorough peer review

- No space constraints or color figure charges

- Immediate publication on acceptance

- Inclusion in PubMed, CAS, Scopus and Google Scholar

- Research which is freely available for redistribution 